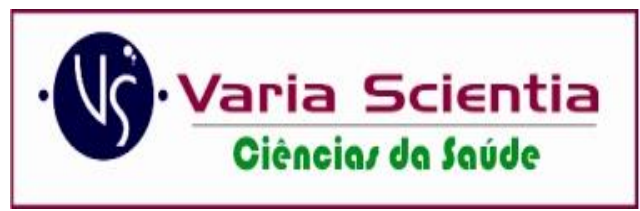

e-ISSN 2446-8118

\title{
TIPO DE ALIMENTOS E FREQUÊNCIA DE CONSUMO POR ESCOLARES DO ENSINO
} FUNDAMENTAL NUM MUNICÍPIO PARANAENSE

\author{
FOOD'S TYPE AND FREQUENCY OF CONSUMPTION BY ELEMENTARY SCHOOL \\ STUDENTS
}

\author{
TIPO DE ALIMENTOS Y LA FRECUENCIA DE CONSUMO DE LOS ALUMNOS DE \\ PRIMARIA
}

\author{
Ana Claudia Ramos de Paula ${ }^{1}$ \\ Gicelle Galvan Machineski ${ }^{2}$ \\ Adreciane Chechi Martins ${ }^{3}$ \\ Beatriz Rosana Gonçalves de Oliveira Toso ${ }^{4}$ \\ Maristela Salete Maraschin ${ }^{5}$
}

\begin{abstract}
RESUMO: Objetivo: Conhecer o tipo de alimento e a frequência de consumo por escolares do ensino fundamental. Método: Pesquisa quantitativa e descritiva, com coleta de dados em duas escolas municipais de um município do oeste do Paraná, a partir da frequência do consumo alimentar e do recordatório alimentar de 24 horas, realizado com534 crianças, entre 06 e 12 anos de idade. Os dados foram analisados por meio de estatística descritiva. O estudo seguiu os preceitos éticos e as crianças e os seus pais consentiram a participação. Resultados: Observou-se que o consumo alimentar é prioritariamente de carboidratos, produtos industrializados, gorduras e açucares, colaborando para o aumento de peso. As crianças fazem cinco refeições ao dia, contando com os lanches na escola, cuja qualidade nutricional não foi satisfatória. Conclusão: É necessário implementar as políticas públicas relacionadas à nutrição do escolar, bem como realizar ações que visem melhorar a educação nutricional nas escolas e, por conseguinte fomentar uma prática alimentar adequada, contribuindo para a prevenção de doenças crônicas.

DESCRITORES: Estado Nutricional; Crianças; Obesidade; Atenção primária à saúde; Cuidado da criança.
\end{abstract}

ABSTRACT: Objective: To know the food's type and frequency of consumption by elementary school students. Method: Quantitative and descriptive research, with data collection in two

\footnotetext{
1 Universidade Estadual do Oeste do Paraná. Enfermeira. Residente do Programa de Residência em Enfermagem Especialidade em Gerenciamento de Enfermagem em Clínica Médica e Cirúrgica, da Universidade Estadual do Oeste do Paraná.

2 Universidade Estadual do Oeste do Paraná. Doutora em Enfermagem. Docente do Curso de Enfermagem e do Programa de Pós-Graduação em Biociências e Saúde da Universidade Estadual do Oeste do Paraná, Campus de Cascavel.

${ }^{3}$ Nutricionista. Colaboradora no projeto "Abordagem da obesidade infanto-juvenil em escolas de ensino fundamental”, desenvolvido com o apoio financeiro da Fundação Araucária.

${ }^{4}$ Universidade Estadual do Oeste do Paraná. Doutora em Ciências. Docente do Curso de Enfermagem e do Programa de Pós-Graduação em Biociências e Saúde da Universidade Estadual do Oeste do Paraná, Campus de Cascavel.

${ }^{5}$ Universidade Estadual do Oeste do Paraná. Mestre em Enfermagem. Docente do Curso de Enfermagem Universidade Estadual do Oeste do Paraná, Campus de Cascavel.
} 
municipal schools of a municipality of the West of Paraná, based on the frequency of food consumption and the 24-hour food recall, performed with 534 children, aged between 06 and 12 years old. Data were analyzed using descriptive statistics. The study followed the ethical precepts and the children and their parents consented to participate. Results: It was observed that food consumption is primarily of carbohydrates, processed products, fats and sugars, collaborating to gain weight. Children make five meals a day, counting on snacks at school, however, their nutritional quality was not satisfactory. Conclusion:It is necessary to implement public policies related to school nutrition, as well as to carry out actions aimed at improving nutritional education in schools and, therefore, to promote an adequate food practice, contributing to the prevention of chronic diseases.

DESCRIPTORS: Nutritional Status; Child; Obesity; Primary Health Care; ChildCare.

RESUMEN: Objetivo: Conocer el tipo de alimentos y la frecuencia de consumo de los alumnos de primaria. Metodo: Investigación cuantitativa y descriptiva, con recolección de datos en dos escuelas municipales de un municipio del Oeste de Paraná, a partir de la frecuencia del consumo alimentario y del recordatorio alimentario de 24 horas, realizado con 534 niños, entre 06 a 12 años. Los datos fueron analizados por medio de estadística descriptiva. El estudio siguió los preceptos éticos y los niños y sus padres accedieron a la participación. Resultados: Se observó que el consumo alimentario es prioritariamente de carbohidratos, productos industrializados, grasas y azúcar, colaborando para el aumento de peso. Los niños hacen cinco comidas al día, contando con los bocadillos en la escuela, sin embargo, la calidad nutricional de esos no fue satisfactoria. Conclusión: Es necesario implementar las políticas públicas relacionadas con la nutrición del escolar, así como realizar acciones para mejorar la educación nutricional en las escuelas y, por consiguiente, fomentar una práctica alimentaria adecuada, contribuyendo a la prevención de enfermedades crónicas.

DESCRIPTORES: Estado Nutricional; Niño; Obesidad; Atención Primaria de Salud; Cuidado del Niño.

\section{INTRODUÇÃO}

A obesidade é uma doença crônica não transmissível, na qual ocorre o acúmulo progressivo da gordura corporal. Nas últimas quatro décadas o número de crianças $\mathrm{e}$ adolescentes obesos, entre cinco e 19 anos, aumentou dez vezes, e se a tendência atual continuar, sem políticas que visem a abordagem integrada dos referidos problemas de saúde pública, até 2022 haverá mais obesidade do que desnutrição moderada e grave nessa faixa etária. Foi o que demonstrou um estudo epidemiológico em que foram analisadas as medidas de peso e altura de cerca de 130 milhões de pessoas, sendo 31,5 milhões entre cinco e 19 anos e, avaliou o índice de massa corporal (IMC) e como a obesidade mudou em todo o mundo entre 1975 e $2016^{1}$.

A Pesquisa Nacional de Saúde em Escolares, realizada em 2015 no Brasil, com alunos do ensino fundamental e médio, analisou os déficits e excessos de peso por meio do IMC. O déficit de peso mostrou prevalência nacional inferior a $3 \%$ e prevalências muito baixas em todas as estratificações realizadas. $\mathrm{O}$ excesso de peso se mostrou mais prevalente entre adolescentes brancos, de escolas particulares, da região sul e dos estratos socioeconômicos mais pobres. As prevalências tendem a ser mais elevadas no sexo feminino, especialmente após 15 anos de idade. No plano nacional, aproximadamente um em cada quatro adolescentes está acima do peso considerado saudável. Além disso, notou-se que o Brasil apresenta tendência consistente e ampla de redução nos valores dos indicadores de déficit nutricional em sua população infantil, adolescente e adulta ${ }^{2: 5}$.

E quando a obesidade se instala na infância, o tratamento é longo e precisa do apoio familiar quanto ao incentivo e 
orientações em relação à alimentação saudável, pois a criança não tem autonomia para tal escolha e, portanto, não tem competência para a reeducação alimentar individualmente ${ }^{3}$.

Nesse sentido, é importante conhecer o comportamento alimentar das crianças. Para tanto, utiliza-se a anamnese seguindo critérios técnicos, que consideram a idade da criança, o objetivo da investigação, condições socioeconômicas e tempo disponível para a avaliação, a fim de favorecer maior fidedignidade aos dados obtidos ${ }^{4}$.

É importante salientar que, no que se refere aos inquéritos alimentares, não existe um método considerado padrão-ouro (teste padrão), pois nenhum dos métodos existentes oferece uma avaliação exata do consumo alimentar. Sendo assim todos são passíveis de erros, contudo é necessário avaliar fatores como aplicabilidade e custo para definir qual método deverá ser utilizado. Dessa forma, para a avaliação dietética, pode-se utilizar o Recordatório Alimentar de 24 horas (R24h), que investiga, por meio de informação verbal, a ingestão alimentar do entrevistado nas 24 horas anteriores a entrevista. Constitui-se num instrumento de rápida aplicação e baixo custo, utilizado a fim de avaliar a dieta do indivíduo, com base na ingestão de nutrientes e energia ${ }^{5}$.

Assim, entende-se que com a utilização da anamnese e do R24h pode-se conhecer os hábitos alimentares das crianças a fim de contribuir para o desenvolvimento de programas intersetoriais, que envolvam a alimentação e a nutrição adequada. Nesse sentido, questiona-se: "Quais os alimentos e com que frequência são consumidos pelas crianças no ensino fundamental?" Para responder a essa pergunta, estabeleceu-se como objetivo conhecer o tipo de alimento e a frequência de consumo por escolares do ensino fundamental.

\section{MÉTODOS}

Trata-se de um estudo quantitativo e descritivo que faz parte de uma pesquisa maior intitulada "Abordagem da obesidade infanto-juvenil em escolas de ensino fundamental", desenvolvido com o apoio financeiro da Fundação Araucária.

A coleta de dados foi desenvolvida em duas escolas municipais da região oeste do Paraná, uma pertencente a área de abrangência de uma unidade básica de saúde da região sul e outra da região norte.

A população do estudo foi composta por 1271 crianças, com faixa etária de seis a 12 anos de idade, sendo 368 da região sul e 873 da região norte. A amostra foi constituída por 534 crianças, o que correspondeu a $42 \%$ da população do estudo. Destas, 178 crianças da região sul e 356 da região norte, correspondendo respectivamente a $48 \%$ e $40 \%$ da população da pesquisa.

Foram incluídas no estudo as crianças da referida faixa etária, cujos pais concordaram com a participação por meio da assinatura do Termo de Consentimento Livre e Esclarecido e cujas crianças aceitaram participar mediante assinatura do Termo de Assentimento Livre e Esclarecido, e que estivessem presentes na escola no período da coleta. Foram excluídas as crianças que, apesar de terem o consentimento dos pais não quiseram participar, tivessem alguma alteração mental ou comportamental autorreferida ou informada pela equipe da escola, ou que foram transferidas para outra escola durante o período da coleta. Sendo assim 737 crianças não participaram da pesquisa, o que corresponde a $58 \%$ da população do estudo.

Os dados foram coletados no período de agosto a outubro de 2017, na escola da região sul, e no período de março a julho de 2018, na escola da região norte. Importante salientar que esse intervalo temporal da coleta se coloca como limitação do estudo, justificada pela morosidade enfrentada pelos pesquisadores em relação ao financiamento da pesquisa, o que impossibilitou que a coleta fosse realizada concomitantemente nas duas escolas.

Essa fase foi realizada nos períodos matutino e vespertino, por meio de um formulário, elaborado pela equipe de pesquisadores, intitulado "Instrumento de Caracterização Sociodemográfica e Clínica", e validado quanto à forma e conteúdo, dividido em 8 itens, contemplando os dados socioeconômicos; a avaliação clínica; situação 
de saúde; e um questionário de frequência de consumo alimentar (em que todo dia se refere ao consumo diário; toda semana se refere a uma vez na semana; de vez em quando se refere a cada 15 dias ou uma vez por mês e; não consome se refere a não consumir tal alimento), em que a criança poderia marcar o mesmo alimento em mais de um item e; recordatório de 24 horas que inclui o tipo e número de refeições diárias (café da manhã, lanche da manhã, almoço, lanche da tarde, jantar e ceia), sendo que o presente estudo utilizou os dois últimos itens. E na coleta dos dados foram consideradas as limitações das respostas das crianças, assim cada item foi explicado e apresentado com linguagem o mais adequada possível para a idade.

Para a análise, os dados foram tabulados e analisados sob a forma da estatística descritiva, sendo apresentados em tabelas para posterior comparação com a literatura disponível acerca da temática em questão. É importante salientar que as respostas dos itens sobre a frequência alimentar e recordatório alimentar de $24 \mathrm{~h}$ somam mais de $100 \%$ do número de participantes, tendo em vista que foram considerados diferentes itens citados pelo mesmo escolar em cada refeição.

Foram observados os aspectos éticos sobre a pesquisa envolvendo seres humanos, cujo projeto de pesquisa foi aprovado pelo Comitê de Ética em Pesquisa da Universidade Estadual do Oeste do Paraná (UNIOESTE), sob parecer $\mathrm{n}^{\circ} 1.872 .666$, CAAE $\mathrm{n}^{\circ}$ 60942716.8.0000.01076.

\section{RESULTADOS}

Dentre os 534 escolares participantes do estudo, a média de idade foi de oito anos. Essas crianças realizavam seis refeições ao dia (café da manhã, lanche da manhã, almoço, lanche da tarde, jantar e ceia), sendo que as principais eram realizadas na escola. Quanto a renda familiar a maioria não soube responder, considerando a limitação da faixa etária dos participantes, mas os que responderam da escola da região sul afirmaram um valor entre ume oito salários mínimos e, da escola da região norte de menos de um a três salários mínimos.

A tabela 1 apresenta a frequência do consumo alimentar quanto a ingesta de doces, frituras, refrigerantes, produtos integrais, frutas, verduras e água, conforme relatos das escolares. 
Tabela 1 - Frequência do consumo alimentar dos escolares. Cascavel, PR, Brasil, 2017-2018

\begin{tabular}{|c|c|c|c|}
\hline Consumo & $\mathrm{n}(\%)$ & n(\%) Região Norte & n(\%) Região Sul \\
\hline \multicolumn{4}{|l|}{ Todo dia } \\
\hline Água & $534(100 \%)$ & $356(100 \%)$ & $178(100 \%)$ \\
\hline Frutas & $228(43 \%)$ & $124(35 \%)$ & $104(59 \%)$ \\
\hline Verduras & $203(38 \%)$ & $119(33 \%)$ & $84(47 \%)$ \\
\hline Doce & $113(21 \%)$ & $86(24 \%)$ & $27(15 \%)$ \\
\hline Fritura & $81(15 \%)$ & $62(17 \%)$ & $19(11 \%)$ \\
\hline Refrigerante & $76(14 \%)$ & $52(15 \%)$ & $24(13 \%)$ \\
\hline Produtos integrais & $64(12 \%)$ & $32(9 \%)$ & $32(18 \%)$ \\
\hline \multicolumn{4}{|l|}{ Toda semana } \\
\hline Refrigerante & $246(46 \%)$ & $160(45 \%)$ & $86(48 \%)$ \\
\hline Frutas & $185(35 \%)$ & $134(38 \%)$ & $51(29 \%)$ \\
\hline Doce & $196(37 \%)$ & $120(34 \%)$ & $76(43 \%)$ \\
\hline Fritura & $180(36 \%)$ & $117(33 \%)$ & $63(35 \%)$ \\
\hline Verduras & $156(29 \%)$ & $102(29 \%)$ & $54(30 \%)$ \\
\hline Produtos integrais & $61(11 \%)$ & $29(8 \%)$ & $32(18 \%)$ \\
\hline Água & $0(0 \%)$ & $0(0 \%)$ & $0(0 \%)$ \\
\hline \multicolumn{4}{|l|}{ De vez em quando } \\
\hline Fritura & $263(49 \%)$ & $171(48 \%)$ & $92(52 \%)$ \\
\hline Produtos integrais & $232(43 \%)$ & $164(46 \%)$ & $68(38)$ \\
\hline Doce & $222(41 \%)$ & $147(41,2)$ & $75(42 \%)$ \\
\hline Refrigerante & $196(37 \%)$ & $139(39 \%)$ & $57(32 \%)$ \\
\hline Verduras & $132(25 \%)$ & $109(31 \%)$ & $23(13 \%)$ \\
\hline Frutas & $109(20 \%)$ & $89(25 \%)$ & $20(11 \%)$ \\
\hline Água & $0(0 \%)$ & $0(0 \%)$ & $0(0 \%)$ \\
\hline \multicolumn{4}{|l|}{ Não consome } \\
\hline Produtos integrais & $155(29 \%)$ & $125(35 \%)$ & $30(17 \%)$ \\
\hline Verduras & $35(6 \%)$ & $23(6 \%)$ & $12(7 \%)$ \\
\hline Frutas & $9(0,1 \%)$ & $6(2 \%)$ & $3(2 \%)$ \\
\hline Fritura & $11(0,2 \%)$ & $4(1 \%)$ & $7(4 \%)$ \\
\hline Refrigerante & $10(0,2 \%)$ & $4(1 \%)$ & $6(3 \%)$ \\
\hline Doce & $4(0,07 \%)$ & $2(0,5 \%)$ & $2(1 \%)$ \\
\hline Água & $0(0 \%)$ & $0(0 \%)$ & $0(0 \%)$ \\
\hline
\end{tabular}

Fonte: dados da pesquisa, 2018.

Ao analisar a frequência de consumo alimentar "todos os dias", 534(100\%) entrevistados referiram ingerir água, seguido das frutas e verduras, para as quais $228(43 \%)$ referiram consumir frutas e 203(38\%) verduras, ambas mais frequentes na região sul, com $104(59 \%)$ e 84(47\%) escolares, respectivamente. $\mathrm{O}$ consumo de doces diariamente foi referido por $113(21 \%)$ participantes, sendo maior o consumo entre os escolares da região norte com $86(24 \%)$ relatos. 
Sobre o consumo de alimentos "toda semana", a maior frequência foi verificada para o refrigerante, dos quais 246(46\%) referiram consumir semanalmente, seguida de $185(35 \%)$ para frutas, $196(37 \%)$ para doces e, $180(36 \%)$ para frituras. A ingesta de frutas semanal foi maior na escola da região norte com $134(38 \%)$ registros, enquanto o consumo de refrigerante, doces e frituras foi mais frequente na região sul, com respectivamente 86 (48\%), 76 (43\%), 63 (35\%) escolares.

Quanto ao consumo "de vez em quando", 263(49\%) dos entrevistados consomem frituras, sendo maior a ingesta na escola da região sul, com $92 \quad(52 \%)$ relatos;232(43\%) relataram produtos integrais e para os doces, 222(41\%) escolares apresentaram esta frequência de consumo, a qual foi semelhante nas duas escolas, seguida pelo consumo de refrigerante, ingerido por 196(37\%) participantes, sendo este mais consumido na escola da região norte por 139 (39\%) participantes.

Entre os alimentos relatados como "não consume", os produtos integrais apresentaram a maior frequência, com $155(29 \%)$ escolares, sendo esta frequência maior na região norte com 125(35\%) registros, seguido por verduras com 35 (6\%) relatos, a qual foi similar entre as duas regiões.

A tabela 2, apresenta os dados em relação ao recordatório alimentar de 24 horas, conforme relatos das crianças das escolas municipais. 
Paula ACR, Machineski GG, Martins AC, Toso BRGO, Maraschin MS

Tabela 2 - Recordatório alimentar de 24 horas. Cascavel, PR, Brasil, 2017-2018.

\begin{tabular}{|c|c|c|c|}
\hline Consumo & $\mathrm{n}(\%)$ & n(\%) Região Norte & n(\%) Região Sul \\
\hline \multicolumn{4}{|l|}{ Café da manhã } \\
\hline Pão & $205(38 \%)$ & $203(57 \%)$ & $2(1 \%)$ \\
\hline Café/leite & $85(15 \%)$ & $78(22 \%)$ & $7(4 \%)$ \\
\hline Bolacha & $75(14 \%)$ & $73(21 \%)$ & $2(1 \%)$ \\
\hline Leite/achocolatado & $65(12 \%)$ & $57(16 \%)$ & $9(5 \%)$ \\
\hline Chá & $45(8 \%)$ & $45(13 \%)$ & $0(0 \%)$ \\
\hline Margarina & $39(7 \%)$ & $39(11 \%)$ & $0(0 \%)$ \\
\hline \multicolumn{4}{|l|}{ Lanche da manhã } \\
\hline Pão/pão doce & $55(10 \%)$ & $45(13 \%)$ & $10(6 \%)$ \\
\hline Lanche da escola* & $49(9 \%)$ & $28(8 \%)$ & $21(12 \%)$ \\
\hline Bolacha & $45(8 \%)$ & $22(6 \%)$ & $23(13 \%)$ \\
\hline Leite/achocolatado & $23(4 \%)$ & $18(5 \%)$ & $5(3 \%)$ \\
\hline Café/leite/chá & $31(5 \%)$ & $16(4,4 \%)$ & $15(8,4 \%)$ \\
\hline Margarina & $10(1 \%)$ & $10(3 \%)$ & $0(0 \%)$ \\
\hline \multicolumn{4}{|l|}{ Almoço } \\
\hline Arroz/risoto & $452(85 \%)$ & $319(90 \%)$ & $133(75 \%)$ \\
\hline Feijão & $406(76 \%)$ & $292(82 \%)$ & $114(64 \%)$ \\
\hline Carnes & $370(70 \%)$ & $264(74 \%)$ & $106(59,5 \%)$ \\
\hline Salada & $97(18 \%)$ & $91(25 \%)$ & $6(3 \%)$ \\
\hline Macarrão & $86(16 \%)$ & $66(19 \%)$ & $20(11 \%)$ \\
\hline Suco/refrigerantes & $32(5 \%)$ & $30(8 \%)$ & $2(1 \%)$ \\
\hline \multicolumn{4}{|l|}{ Lanche da tarde } \\
\hline Lanche da escola* & $133(25 \%)$ & $133(38 \%)$ & $0(0 \%)$ \\
\hline Pão & $122(23 \%)$ & $89(25 \%)$ & $33(19 \%)$ \\
\hline Bolacha & $96(17 \%)$ & $77(22 \%)$ & $19(11 \%)$ \\
\hline Frutas & $61(11 \%)$ & $39(11 \%)$ & $22(12 \%)$ \\
\hline Sucos & $31(6 \%)$ & $27(8 \%)$ & $4(2 \%)$ \\
\hline Chá/leite/achocolatado & $44(8 \%)$ & $25(7 \%)$ & $19(\%)$ \\
\hline \multicolumn{4}{|l|}{ Jantar } \\
\hline Arroz/risoto & $339(63 \%)$ & $277(78 \%)$ & $62(35 \%)$ \\
\hline Feijão & $309(58 \%)$ & $261(74 \%)$ & $48(27 \%)$ \\
\hline Carnes & $264(49 \%)$ & $214(60 \%)$ & $50(28 \%)$ \\
\hline Salada & $89(17 \%)$ & $67(19 \%)$ & $22(12 \%)$ \\
\hline Macarrão & $76(14 \%)$ & $64(18 \%)$ & $12(7 \%)$ \\
\hline Batata/mandioca & $44(8 \%)$ & $44(12 \%)$ & $0(0 \%)$ \\
\hline \multicolumn{4}{|l|}{ Ceia } \\
\hline Água & $56(10 \%)$ & $56(16 \%)$ & $0(0 \%)$ \\
\hline Leite/achocolatado & $35(6 \%)$ & $26(7 \%)$ & $9(5 \%)$ \\
\hline Iogurte & $23(4 \%)$ & $23(6 \%)$ & $0(0 \%)$ \\
\hline Frutas & $22(4 \%)$ & $19(5 \%)$ & $3(2 \%)$ \\
\hline Bolacha & $14(2 \%)$ & $12(3 \%)$ & $2(1 \%)$ \\
\hline Doce & $13(2 \%)$ & $9(3 \%)$ & $4(2 \%)$ \\
\hline
\end{tabular}

Observação: como Lanche da escola* foram citados: arroz, feijão, risoto, batata, mandioca, polenta, sagu, arroz doce, torta, macarrão, carnes e legumes.

Fonte: dados da pesquisa, 2018. 
No café da manhã 205(38\%) escolares referiram ingerir pão; $85(15 \%)$ tomar café ou leite e; 75(14\%) comer bolacha. Sendo que a maior frequência de consumo dos alimentos mencionados encontra-se na escola da região norte com 203(57\%), 78(22\%) e 73(21\%) das respostas, respectivamente.

No lanche da manhã 55(10\%) escolares relatam consumir pão, apresentando maior frequência de consumo na escola da região norte com 45(13\%) relatos. $\mathrm{Na}$ sequência, 49(9\%) fazem o lanche da escola e; 45(8\%) comem bolacha, sendo esses mais consumidos na escola da região sul, com respectivamente, $21(12 \%)$ e $23(13 \%)$ respostas.

No almoço, 452(85\%) consomem arroz ou risoto; $406(76 \%)$ feijão e, $370(70 \%)$ carnes, todos mais frequentes na escola da região norte com 319 (90\%), $292(82 \%)$ e 264 (74\%), respectivamente.

Para o lanche da tarde, os escolares referem consumir $133(25 \%)$ o lanche da escola; 122(23\%) pão e 96(17\%) bolachas. Tais alimentos foram os mais relatados na escola da região norte, sendo que as repostas tiveram respectivamente $133(38 \%), 89(25 \%)$ e $77(22 \%)$ relatos.

No jantar os resultados se referem aos mesmos alimentos do almoço, em que $339(63 \%)$ consomem arroz ou risoto; $309(58 \%)$ feijão e, 264(49\%) carnes. As maiores frequências de resposta encontram-se na escola da região norte com respectivamente 277 (78\%), $261(74 \%)$ e 214 $(60 \%)$ escolares.

$\mathrm{Na}$ ceia, $56(10 \%)$ escolares relatam consumir água, seguido por leite ou achocolatado, 35(6\%), iogurte 23(4\%) e frutas $22(4 \%)$. Os resultados da escola da região norte evidenciam a maior frequência no consumo desses alimentos com $56(15,7 \%)$, $26(7,3 \%), 23(6,4 \%)$ e $19(5,3 \%)$ relatos, respectivamente. Importante salientar que essa refeição teve a menor frequência entre as referidas pelos escolares.

\section{DISCUSSÃO}

Observou-se elevado consumo de doces pelas crianças entrevistadas. As suas escolhas alimentares podem ser decorrentes das condições financeiras, mais precárias na região norte do município, associadas a pouca ou equivocada informação nutricional. E ainda, a falta de conhecimento acerca das funções dos alimentos no organismo e de escolhas nutricionais mais saudáveis, as quais interferem nas condições atuais e futuras da saúde das crianças.

$\mathrm{O}$ excesso de doces na dieta resulta em malefícios para a saúde, visto que esses produtos alimentícios são ricos em açúcares e podem resultar em doenças como obesidade, diabetes tipo II, aumento de triglicerídeos, entre outras ${ }^{7}$.

Pesquisa que corrobora os resultados desse estudo foi realizada na cidade de Cotonou, República do Benin, África, a qual coletou dados de 100 crianças entre sete e 13 anos que frequentavam escolas primárias e identificou que o consumo de frutas e vegetais é baixo para todas as crianças. No entanto, há uma melhor diversificação alimentar e uma preponderância de produtos doces e de animais em crianças obesas ${ }^{8}$.

Em relação ao consumo semanal de frituras, entende-se que a escolha por alimentos fritos está relacionada ao fato de serem alimentos que têm menores custos financeiros, demandam menos tempo de preparo e são mais agradáveis ao paladar, o que representa uma falsa vantagem para os pais, que preparam e, automaticamente, estimulam o consumo desses alimentos pelas crianças. Entretanto, o consumo elevado de frituras está associado a doenças como: dislipidemias, doenças cardiovasculares, acidente vascular cerebral, obesidade, entre outras ${ }^{4}$.

$\mathrm{O}$ índice de consumo de refrigerantes foi alto, $46 \%$ dos escolares consomem esse produto toda semana. Essas bebidas são ricas em substâncias como açúcares, conservantes e corantes, os quais não são necessários à saúde humana. Além de não trazer benefícios para as crianças, em fase de crescimento e desenvolvimento. $\mathrm{O}$ uso frequente desses produtos pode resultar no desenvolvimento de doenças como: obesidade, diabetes tipo II, dislipidemias, agravo de problemas inflamatórios relacionados à alimentação e às 
alergias alimentares relacionadas aos corantes $^{4,7}$.

Revisão sistemática de estudos de coorte e experimentais que investigaram a influência do consumo de bebidas adoçadas com açucar e o risco de obesidade entre crianças e adolescentes identificou que, em estudos com metodologia forte, encontrou-se associação positiva entre os dois fatores, especialmente em crianças com excesso de peso?.

As crianças entrevistadas relatam baixo consumo de produtos integrais, possivelmente devido aos custos serem mais elevados ou por não agradar aos seus paladares. Esses produtos deveriam ser consumidos em maiores quantidades pelas crianças, pois são ricos em substâncias que melhoram o funcionamento do organismo, como as fibras alimentares. Essas melhoram a função intestinal e a absorção de gorduras, diminuindo as dislipidemias e o índice glicêmico dos alimentos. Também atuam aumentando a sensação de saciedade ${ }^{10}$.

Todas as crianças referiram consumir água diariamente, porém observa-se que o consumo de frutas foi menor do que $o$ recomendado, considerando que menos da metade consome frutas diariamente, evidenciando que a ingesta está abaixo do preconizado pela Organização Mundial da Saúde (OMS), que é de pelo menos 3 (três) porções de frutas ao dia. As frutas sã o ricas em vitaminas, em minerais e em fibras, exercem função reguladora do organismo e seu uso frequente está relacionado à prevenção de doenças, devido aos seus compostos fotoquímicos que beneficiam a saúde, agindo como antioxidantes ${ }^{4}$.

O consumo de verduras também ficou aquém do necessário, pois menos da metade das crianças têm o hábito de consumir verduras e legumes todos os dias. Isso pode estar relacionado à falsa impressão de que esses alimentos são caros e, também, na demanda que envolve o consumo, como o tempo de higienização e preparo, que parecem ser mais trabalhosos se comparados aos outros alimentos. Além disso, o sabor das frutas muitas vezes não é atrativo às crianças.

As verduras e legumes são alimentos reguladores no nosso organismo, seus compostos agem prevenindo doenças; melhorando as funções intestinais por serem ricos em fibras; aumentando a saciedade e fornecendo vitaminas e minerais contribuindo para o desenvolvimento das funções vitais de maneira mais equilibrada ${ }^{10}$.

Em relação aos resultados do recordatório alimentar de 24 horas, observa-se que o café da manhã, quando consumido, é composto principalmente por café com leite, pão e margarina, mostrando-se pouco nutritivos. Para melhorar o café da manhã, é necessário aumentar o consumo de proteínas e substituir aqueles por itens semelhantes que sejam mais saudáveis, tendo em vista que o café da manhã é essencial para melhorar a cognição das crianças ${ }^{11,12}$.

No lanche da manhã, a maioria das crianças recebe a alimentação fornecida pela escola. Nesse caso há um conflito, visto que, a escola tem a obrigação de fornecer alimentos saudáveis, porém a verba destinada à alimentação é baixa, o que faz com que se comprem alimentos mais baratos e com baixos valores nutricionais. Além disso, uma das escolas está situada em uma região da cidade considerada vulnerável, em que a maioria das famílias têm poucos recursos financeiros e dificuldades para manter uma alimentação adequada.

A escola tem influência sobre a formação dos indivíduos e deve promover práticas preventivas de educação em saúde, de acordo com o Programa Saúde na Escola (PSE), que visem a promoção da saúde, prevenção e controle das doenças crônicas não transmissíveis, desenvolvendo a vigilância e a avalição nutricional, ações de educação nutricional e acompanhamento dos casos de risco. Os espaços escolares também devem ser avaliados para que não ocorra dentro das escolas a venda de alimentos considerados não saudáveis ${ }^{13}$.

Observa-se que o almoço é a refeição mais equilibrada nutricionalmente, a maioria das crianças consome arroz e feijão, considerado a dupla perfeita da nutrição, pois proporciona a ingestão de carboidratos e proteínas e atende parte das necessidades nutricionais. No entanto, o consumo de verduras e legumes nessa refeição é baixo, assim como o de produtos integrais, o que 
revela um déficit de outros nutrientes que também são importantes para o desenvolvimento, como vitaminas, minerais e fibras ${ }^{4,10}$.

Nos lanches da manhã e da tarde, fornecidos pela escola, percebeu-se a influência das limitações de verbas que as escolas recebem e são destinadas à alimentação, o que dificulta a escolha de alimentos ricos em nutrientes, pois é necessário optar por alimentos com custos mais acessíveis. Assim, há um consumo elevado de alimentos pobres em nutrientes o que tende a ser prejudicial à saúde das crianças e contribuir para o desenvolvimento de sobrepeso, obesidade e outras doenças ${ }^{14}$.

No jantar, o consumo de alimentos é semelhante ao consumo do almoço, envolvendo arroz e feijão. $\mathrm{Na}$ ceia os escolares, que realizam essa refeição, consomem prioritariamente leite e achocolatados. Os achocolatados são produtos alimentícios ricos em açucares e pobres em nutrientes benéficos à saúde e seu consumo frequente está associado ao desenvolvimento de sobrepeso e obesidade, e a diabetes tipo II, o que resulta em problemas de saúde na infância e consequência para a vida adulta $^{10,14}$.

Estudo queanalisou os dados de 9.701 participantes do Inquérito Nacional de Saúde e Nutrição dos Estados Unidos, 20012010, com idades compreendidas entre os dois e os 11 anos, identificou que a insegurança alimentar, ou seja, escolhas alteradas e padrões de consumo não uniformes, está associada a um aumento do risco de obesidade em crianças nessa faixa etária $^{15}$.

\section{CONCLUSÃO}

$\mathrm{O}$ estudo sugere que as crianças entrevistadas consomem prioritariamente carboidratos, produtos industrializados, açúcares e gorduras. Esse tipo de alimentação colabora para o desenvolvimento de sobrepeso e obesidade. Além disso, esses alimentos são pobres em nutrientes essenciais para o crescimento e desenvolvimento saudável dessas crianças, como vitaminas, minerais e fibras.

Consumir carboidratos em excesso, resulta no acúmulo de gorduras no organismo na forma de triglicerídeos, o que favorece o desenvolvimento de doenças cardiovasculares, que podem comprometer a qualidade de vida dessas crianças e resultar em agravos de saúde na vida adulta.

O recordatório alimentar de 24 horas é importante para fazer o levantamento do tipo de alimentos consumidos. Porém, o estudo apresenta limitações pelo fato de ter sido realizado com crianças a partir de seis anos e, apesar da metodologia ser amplamente utilizada, as respostas podem não ser tão fidedignas quanto se espera. Ainda, como o estudo foi apenas em duas escolas, pode não representar a realidade dos escolares do município. Além disso, o espaço temporal da coleta de dados entre uma escola e outra, tendo em vista o atraso do repasse dos recursos para a viabilização de tal atividade, também se coloca como limitação.

Portanto, faz-se necessário o desenvolvimento de estudos com maior abrangência e que incluam como sujeitos os familiares e professores da escola, utilizandose de métodos mistos para a coleta e análise dos dados. Além disso, é preciso realizar intervenções nas escolas para as crianças e familiares, visando melhorar a educação nutricional das crianças e prevenir os agravos decorrentes como a obesidade e as doenças crônicas não transmissíveis.

\section{AGRADECIMENTOS}

À Fundação Araucária de Apoio ao Desenvolvimento Científico e Tecnológico do Paraná pelo financiamento do projeto maior.

\section{REFERÊNCIAS}

1. Abarca-Gómez L, Abdeen ZA, Hamid ZA, Abu-Remeileh NM, Acosta-Cazares B, Acuin $\mathrm{C}$ et al. Worldwide trends in body-mass index, underweight, overweight, and obesity from 1975 to 2016: a pooled analysis of 2416 population-based measurement studies in 128.9 million children, adolescents, and 
adults. Lancet. 390(10113): [online] [acesso em 2019 Mar 12]. Disponível em: https://www.thelancet.com/journals/lancet/arti cle/PIIS0140-6736(17)32129-3/fulltext

2. Conde WL, Mazzeti CMS, Silva JC, Santos IKS, Santos AMR. Estado nutricional de escolares adolescentes no Brasil: a Pesquisa Nacional de Saúde dos Escolares 2015. Rev. bras. epidemiol. e180008: [online] [acesso em 2019 Mar 26] ; 21( Suppl 1 ): Disponível em: http://www.scielo.br/scielo.php?script=sci_art text\&pid=S1415-

790X2018000200418\&lng=pt

3. Guerreiro M, Sousa E. O papel do enfermeiro na obesidade infantil. Distrito Federal: FICIPLAC; 2015.

4. Tirapegui J. Nutrição fundamentos e aspectos atuais. 3a ed, Campinas: Atheneu; 2013.

5. Lopes BA, Czepielewski MA. O recordatório de 24 horas como na avaliação do consumo alimentar de cálcio, fósforo e vitamina $D$ em crianças e adolescentes de baixa estatura. Rev. Nutr. 23(1): [online] [acesso em 2019 Mar 26]. Disponível em: http://www.scielo.br/scielo.php?script=sci_art text\&pid=S1415-

$52732010000100008 \& \operatorname{lng}=$ en

6. Brasil. Resolução $\mathrm{n}^{\circ}$ 510, de 07 de abril de 2016. [online] [acesso em 2018 Out 15]. Disponível em: http://conselho.saude.gov.br/resolucoes/2016/ Reso510.pdf

7. Dornelles AD, Anton MC, Pazzinato A. O papel da sociedade e da família na assistência ao sobrepeso e à obesidade infantil: percepção de trabalhadores da saúde em diferentes níveis de atenção. Revista Saúde Soc. 2014;23(4):1275-1287.

8. Flenon A, Mitchikpe CES, Hounhouigan DJ. Facteurs socioéconomiques et de mode de vie associés à l'obésité chez les enfants d'âgescolaire fréquentant les écoles primaires privées de Cotonou. Int. J. Biol. Chem. Sci.12(1): 217-232. [online] [acesso em 2019 Abr 02]; Disponível em: https://www.ajol.info/index.php/ijbcs/article/v iew/172438

9. Della Torre SB, Keller A, Depeyre JL, Kruseman M. Sugar-Sweetened Beverages and Obesity Risk in Children and Adolescents: A Systematic Analysis on How Methodological Quality May Influence Conclusions. Journal of the Academy of Nutrition and Dietetics. 116(4): [online] [acesso em 2019 Mar 30]. Disponível em: https://www.sciencedirect.com/science/article /pii/S2212267215006516

10. Cozzolino SMF. Biodisponibilidade de nutrientes. 5a ed. Barueri (SP): Manole; 2016.

11. Fisberg M, Previdelli NA, Del'Arco APWT, Tosatti A, Almeid CAN. Hábito alimentar nos lanches intermediários de crianças escolares brasileiras de 7 a 11 anos: estudo em amostra nacional representativa. Inter.JournalNutrology. 2016 Set-Dez; 9(4):225-236.

12. Souza IGS, Freitas AC, Abreu CLM, Braggion GF, Santos MX, Souza IGS et al. Nutrição clínica, esportiva, saúde coletiva e gestão de qualidade em serviços de alimentação. Florianópolis; 2015.

13. Silva RSC, Passos TUA. Adequação dos cardápios da alimentação escolar em creches segundo a pirâmide alimentar infantil. JHBS. 2018; 3:273-278.

14. Rech RR, Halpern R, Costanzi CB, Bergmann MLA, Alli LR, Mattos AP et al. Prevalência de obesidade em escolares de 7 a 12 anos de uma cidade Serrana do RS, Brasil. Rev, Bras. Cineantropom Desempenho Hum. 2010; 12 (2): 90-97.

15. Kaur J, Molly ML, Ogden CL. The Association between Food Insecurity and Obesity in Children-The National Health and Nutrition Examination Survey. JAND. 115(5): [online] [acesso em 2019 Mar 23]. Disponível em: https://jandonline.org/article/S22122672(15)00006-4/fulltext

Recebido em: 09.07.2020. Aprovado em: 29.07.2020. 